\title{
Half a century of studying adaptability and stability in maize and soybean in Brazil
}

\author{
Wender Santos Rezende ${ }^{1 *} \odot$, Cosme Damião Cruz $^{2} \odot$, Aluízio Borém ${ }^{1 \odot}$, Renato Domiciano Silva Rosado ${ }^{3}$
}

\begin{abstract}
'Universidade Federal de Viçosa - Depto. de Fitotecnia, Av. Peter Henry Rolfs, s/n - 36570-900 - Viçosa, MG - Brasil. 2Universidade Federal de Viçosa - Depto. de Biologia Geral, Av. Peter Henry Rolfs, s/n - 36570-900 - Viçosa, MG Brasil.

3Universidade Federal de Viçosa - Depto. de Estatística Aplicada e Biometria, Av. Peter Henry Rolfs, s/ -36570 900 - Viçosa, MG - Brasil.

${ }^{*}$ Corresponding author < wendersrezende@gmail.com>
\end{abstract}

Edited by: Alencar Xavier

Received July 30, 2019

Accepted September 30, 2019
ABSTRACT: The study of adaptability and stability underlies the cultivar recommendation process for all crops. There is a considerable number of statistical methods available for this purpose, but little is known about their actual adoption by the Brazilian scientific community. The objective of this study was to carry out a systematic review of the scientific literature on the adaptability and stability methods used in maize and soybean in Brazil from scientific articles published between 1970 and 2017 in Brazilian journals. Article searches were carried out in journals indexed through the SciELO database. The articles were classified according to the year of publication and the adaptability and stability methods used. We also evaluated the pattern of association between methods. We found 113 articles on adaptability and stability in maize and soybean, in which 21 methods were listed. The most commonly used method was the Eberhart and Russell methodology. The Cruz, Torres, and Vencovsky along with the AMMI methods were also widely used. The number of articles using most methods decreased in the current decade, except for the GGE Biplot, MHPRVG, and Centroid methods. In studies with more than one method, the methods were more likely to be used together with the Eberhart and Russell methodology. Adaptability and stability in maize and soybean have been widely studied over the last several decades in Brazil, although the number of publications on this subject has decreased over this time period.

Keywords: Zea mays L., Glycine max (L.) Merril, genotype $\times$ environment interaction, adaptation, cultivar recommendation

\section{Introduction}

The genotype by environment (GE) interaction is the differential behavior of the genotypes in relation to environmental variations. This may cause inconsistency in the ranking of genotypes between environments and thus hinder the selection and recommendation of cultivars (Elias et al., 2016). In order to minimize the negative effects of GE interaction, the studying of adaptability and stability provides important information for the selection and recommendation of cultivars (Silva and Duarte, 2006).

Adaptability and stability are the ability of genotypes, respectively, to respond favorably to environmental improvement and to have highly predictable behavior in relation to environmental changes (Cruz et al., 2012). Several statistical methods have been proposed for studying adaptability and stability. These methods can be classified according to the statistical approach adopted, which is based on analysis of variance, linear regression and multivariate analysis (Eeuwijk et al., 2016).

The considerable number of methods pertaining to the study of adaptability and stability indicates the complexity of the subject and the difficulty of the process of selecting the most appropriate method. Often there is no agreement among methods. Thus, the definition of which cultivar will be recommended will depend on the method adopted (Cargnelutti Filho et al., 2009). There are many studies available in the scientific literature that discuss and compare the methods, which may aid in the selection process (Eeuwijk et al., 2016; Gauch et al., 2008; Silva and Duarte, 2006; Yan et al., 2007).
However, the selection process can be more successful if there is a detailed understanding of the adoption and preference for certain methods by the scientific community. This understanding can be obtained from a systematic review of the scientific literature - a replicable, scientific and transparent process - that allows for synthesizing the knowledge produced in an area of study and identifying the methods adopted in the existing body of research (Medina and Pailaquilén, 2010; Tranfield et al., 2003). A systematic review focused on articles for maize and soybean crops may be representative of the reality of adaptability and stability studies in Brazil, since these crops are widely researched and are the most cultivated crops by land area in this country.

Thus, the objective of this study was to carry out a systematic review of the scientific literature on the adaptability and stability methods used in maize and soybean in Brazil from scientific articles published between 1970 and 2017 in Brazilian journals.

\section{Materials and Methods}

Selection of the articles was carried out initially using the Scientific Electronic Library Online (SciELO) database. The searches were carried out based on keywords and Boolean operators in Portuguese and English on 16 Mar 2018, using the following terms: (adaptability OR stability OR GEI OR (genotype AND environment AND interaction) OR (GE AND interaction)) AND (soybean OR corn OR maize). 
Articles published between 1970 and 2017 were searched. Only articles published in Brazilian scientific journals were considered during the search in SciELO. However, the origin of authors and experiments were not taken into consideration. Since most of the journals considered in this study were indexed in SciELO after 1970, mainly from the 2000s, complementary searches were carried out on websites and printed versions of these journals in order to cover the whole target period (1970 to 2017). Journals released after 1970 were also taken into account in this study. The articles found by the searches were previously selected simply on the basis of reading the title. Subsequently, the articles were verified in full in order to confirm that they really addressed adaptability and stability studies on maize or soybean in Brazil.

The articles found were classified according to the year and decade of publication (1970-1979, 19801989, 1990-1999, 2000-2009 or 2010-2017), the scientific journal in which they were published, the participating institutions, the trait evaluated, the software used, and the methods of adaptability and stability used. For classification of the articles as regards the participating institutions, the institution of each author of the work was considered. In addition, the institutions were classified as public or private.

The methods used in each article were identified by reading the Materials and Methods section. Articles classified as "methodological" were discarded from this study, i.e., those articles whose focus was to study, compare or propose methods instead of applying the methods to the identifying of cultivars with greater adaptability and stability. In addition, the methods were classified as per the statistical approach used according to reports available in the scientific literature (Cruz et al., 2012; Eeuwijk et al., 2016; Silva and Duarte, 2006).

After this, the most commonly used methods and the crop in which each method predominated were verified. Due to the large number of methods listed, the analyses and discussion mainly addressed the methods used in at least four articles. The methods applied in less than four articles were classified as "others".

As the sample size of maize and soybean (number of published articles per crop) was different, the methods adopted were compared by the relative frequency in each crop as follows:

$$
R F_{i j}=\frac{C_{i j}}{A_{j}} \times 100
$$

where: $\mathrm{RF}_{\mathrm{ij}}$ is the relative frequency of the $i$ th method in the $j$ th crop (maize or soybean); $C_{i j}$ the number of citations of the ith method (number of articles in which the method was applied) in the $j$ th crop, and $\mathrm{A}_{\mathrm{j}}$ the number of articles published in the jth crop.

The number of environments (locations or years) and genotypes studied in the articles were evaluated. The number of federative units, since Brazil is a union of 27 federated units (26 states and one Federal District; http://www.agricultura.gov.br/sfa), covered by the multi-environment trials (METs) of each article was also evaluated. In order to compare the means of these three characteristics, the confidence interval (CI) of 95 $\%$ was calculated. Furthermore, the number of articles published and the adoption of each method number of articles in which a given method was applied) per decade was evaluated, both in maize and soybean. In addition, the average annual rate of publications in each crop was calculated in order to better compare decades since the current decade, beginning in 2010, consisted of only eight years at the time of analysis (2010 to 2017).

The number of methods applied in each article was evaluated for both crops. The equivalence coefficient between methods was calculated since several articles used more than one method. This coefficient measures the probability of methods co-occurring in the same article and was calculated by the following equation:

$$
E_{i j}=\frac{F_{i j}^{2}}{F_{i} \times F_{j}}
$$

where: $E_{i j}$ is the equivalence coefficient between the $i$ th and $j$ th methods; $\mathrm{F}_{\mathrm{i}}$ and $\mathrm{F}_{\mathrm{j}}$ the absolute frequencies (occurrences) of the $i$ th and $j$ th methods, respectively; and $\mathrm{F}_{\mathrm{ij}}$ the frequency with which the $i$ th and $j$ th methods occur in the same article (co-occurrence).

A graph, termed an association network among methods, was made from the matrix of equivalence coefficients $\left(E_{i j}\right)$ between methods. This graph was composed only of the methods applied in at least four articles. The Fruchterman-Reingold algorithm (Fruchterman and Reingold, 1991) was used to create the association network, in which only $\mathrm{E}_{\mathrm{ij}} \geq 0.015$ associations were highlighted. The thickness of the lines (edges) that connected the methods (vertices) was directly proportional to the $E_{\mathrm{ij}}$ value. The qgraph package (Epskamp et al., 2012) from R software (v. 3.4.3; R Core Team, 2017) was used to make the association network. The degree centrality of the association network was calculated, and the degree of each method was given by the number of connections $\left(E_{i j} \geq 0.015\right)$ with other methods.

The other analyses of this work were also carried out using the $\mathrm{R}$ software program and the graphics were generated by the ggplot2 package (Wickham, 2009).

\section{Results and Discussion}

The search was performed in the SciELO database for articles on adaptability and stability in maize or soybean in 14 Brazilian scientific journals (Figure 1). From the complete search in these journals (search using SciELO for, the websites of journals in the printed versions), 130 articles were found addressing adaptability and stability in maize or soybean. Of these, 17 articles were discarded because they were considered "methodological". This left a total of 113 articles (75 on maize and 38 on soybean). 
The study of the GE interaction, usually followed by the adaptability and stability study, is based on METs including several genotypes evaluated in several environments from different locations and years. In the articles considered in this study, the average number of environments evaluated in maize was 13.1 and in soybean 20.5 (Figure 2). In the same articles, the average number of genotypes evaluated in maize was 24.8 and in soybean 18.9. There was an overlap of the confidence interval in both characteristics, indicating that there were no significant differences between maize and soybean.

The METs of maize were wider than those of soybean, covering an average of 2.68 and 1.53 federative units, respectively. Unlike maize, the adaptation area of soybean is highly influenced by the photoperiod, which varies according to the latitude of the location. This fact contributes to the occurrence of the genotype $\times$ latitude interaction in soybean, mainly in METs that includes sites with great latitudinal distance (Alliprandini et al., 2009). For this reason, the soybean cultivars are

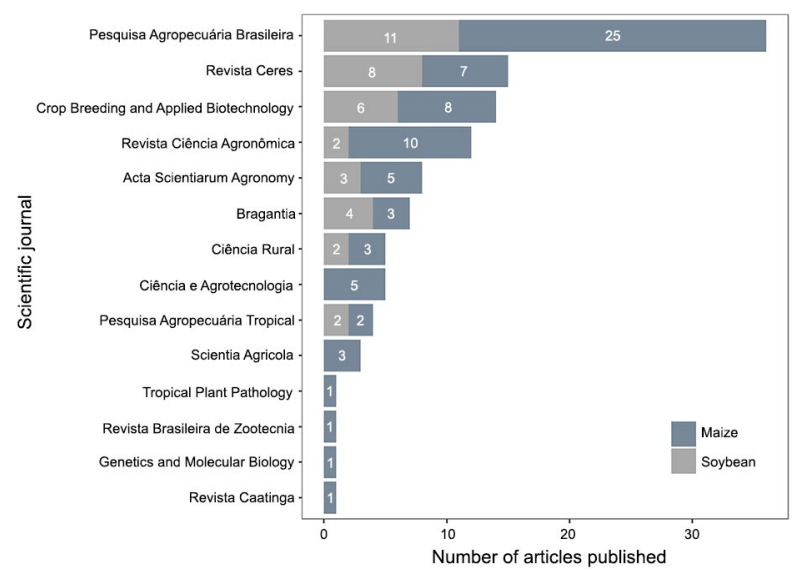

Figure 1 - Number of articles published addressing studies of adaptability and stability in maize or soybean in different Brazilian scientific journals indexed by the SciELO database. usually recommended for regions with a more limited distribution compared to maize.

The majority of articles in this domain have approached the adaptability and stability of the grain yield (101 of the 113 articles listed in this study). Other traits found were disease severity (eight articles), such as grey leaf spot (maize) and Asian soybean rust (soybean), dry matter production (four articles), and grain expansion capacity in popcorn (three articles).

Fifty-eight participating institutions were listed in the articles. The institutions that participated in the most articles were the Brazilian Agricultural Research Corporation (EMBRAPA; present in 48 articles, which represents $42 \%$ of the total articles), the Federal University of Viçosa (UFV; present in 25 articles, which represents $22 \%$ of the total), the Federal University of Lavras (UFLA; present in 15 articles, which represents $13 \%$ of the total), and the Luiz de Queiroz College of Agriculture (ESALQ - USP; present in 14 articles, which represents $12 \%$ of the total). There was participation of at least one public institution in all articles, and private institutions participated in only 10 articles.

Only half of the 113 articles (56 articles) mentioned the computer program used to do the analyses of adaptability and stability. In these 56 articles, the computer programs listed were Estabilidade, Genes, GGE biplot, R, SAS, Selegen and Statistica. The most frequently utilized computer programs were Genes (35 articles) and SAS (13 articles).

Twenty-one methods applied in the study of adaptability and stability were mentioned in the articles (Table 1). The most adopted method for both crops was Eberhart and Russell, which was applied in 48 articles (42\% of total articles; Figure 3). This method was proposed in 1966 and is one of the earliest methods applied to the study of adaptability and stability (Eberhart and Russell, 1966). Eberhart and Russell based their approach on simple linear regression composed of a regression coefficient $\left(\beta_{\mathrm{i}}\right)$, which estimates adaptability, and the variance of the regression deviation $\left(\sigma_{d i}^{2}\right)$, which estimates stability (predictability). According
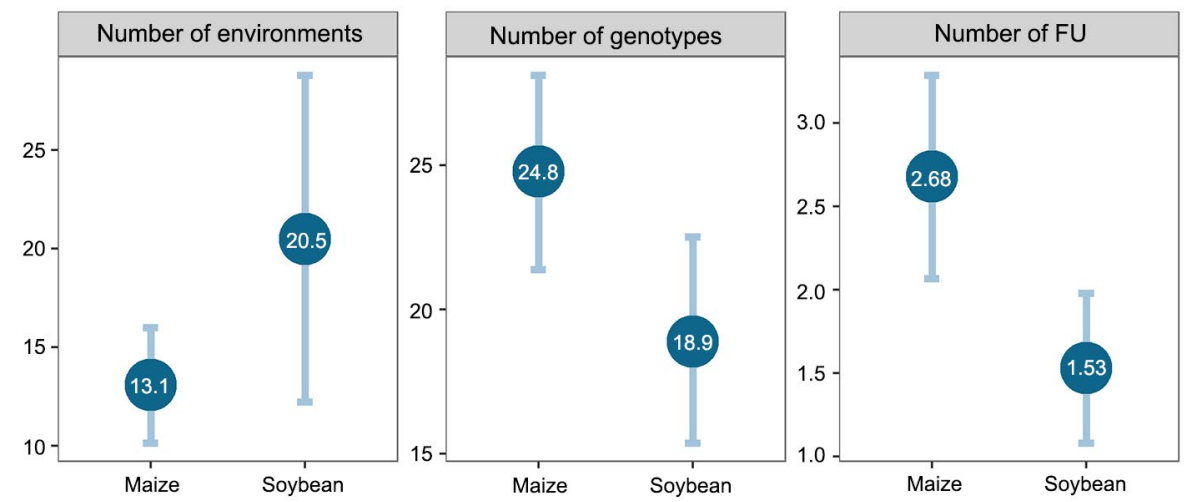

Figure 2 - Average number of environments, genotypes and federative units (FU) and the respective confidence intervals (95\%) that comprise the METs evaluated in the articles on maize and soybean. 
Table 1 - Adaptability and stability methods used in the articles selected in this work and number of articles in which each method was used.

\begin{tabular}{|c|c|c|c|}
\hline Method & Classification & $\begin{array}{l}\text { Year of } \\
\text { release }\end{array}$ & $\begin{array}{l}\text { Number of } \\
\text { articles }\end{array}$ \\
\hline Traditional $^{1}$ & ANOVA & 1938 & 2 \\
\hline Plaisted and Peterson ${ }^{1}$ & ANOVA & 1959 & 3 \\
\hline Wricke $^{1}$ & ANOVA & 1965 & 10 \\
\hline Schmildt ${ }^{2}$ & ANOVA & 2005 & 1 \\
\hline Eberhart and Russell ${ }^{1}$ & Linear regression & 1966 & 48 \\
\hline $\begin{array}{l}\text { Verma, Chahal and } \\
\text { Murty }{ }^{1}\end{array}$ & Bi-segmented regression & 1978 & 3 \\
\hline Silva and Barreto ${ }^{1}$ & Bi-segmented regression & 1985 & 1 \\
\hline $\begin{array}{l}\text { Cruz, Torres, and } \\
\text { Vencovsky }{ }^{1}\end{array}$ & Bi-segmented regression & 1989 & 32 \\
\hline $\begin{array}{l}\text { Bi-segmented } \\
\text { discontinuous model }{ }^{3}\end{array}$ & Bi-segmented regression & 1994 & 3 \\
\hline Lin and Binns ${ }^{4}$ & Nonparametric & 1988 & 10 \\
\hline Kang $^{5}$ & Nonparametric & 1988 & 1 \\
\hline Huehn ${ }^{4}$ & Nonparametric & 1990 & 1 \\
\hline Annicchiarico ${ }^{4}$ & Nonparametric & 1992 & 11 \\
\hline Carneiro 4 & Nonparametric & 1998 & 8 \\
\hline Centroid 6 & Nonparametric & 2005 & 8 \\
\hline $\mathrm{AMMI}^{7}$ & Multivariate analysis & 1988 & 19 \\
\hline GGE Biplot ${ }^{7}$ & Multivariate analysis & 2000 & 9 \\
\hline MHPRVG $^{8}$ & Mixed models & 2002 & 4 \\
\hline HMGV $^{8}$ & Mixed models & 2002 & 1 \\
\hline RPGV8 & Mixed models & 2002 & 1 \\
\hline Toler $^{4}$ & Nonlinear regression & 1990 & 2 \\
\hline
\end{tabular}

These methods were described by ${ }^{1} \mathrm{Cruz}$ et al. (2012), ${ }^{2} \mathrm{Schmildt}$ and Cruz (2005), ${ }^{3}$ Storck and Vencovsky (1994), ${ }^{4}$ Cruz et al. (2014), ${ }^{5}$ Kang (1988), ${ }^{6}$ Rocha et al. (2005), ${ }^{7}$ Eeuwijk et al. (2016) and ${ }^{8}$ Resende (2002).

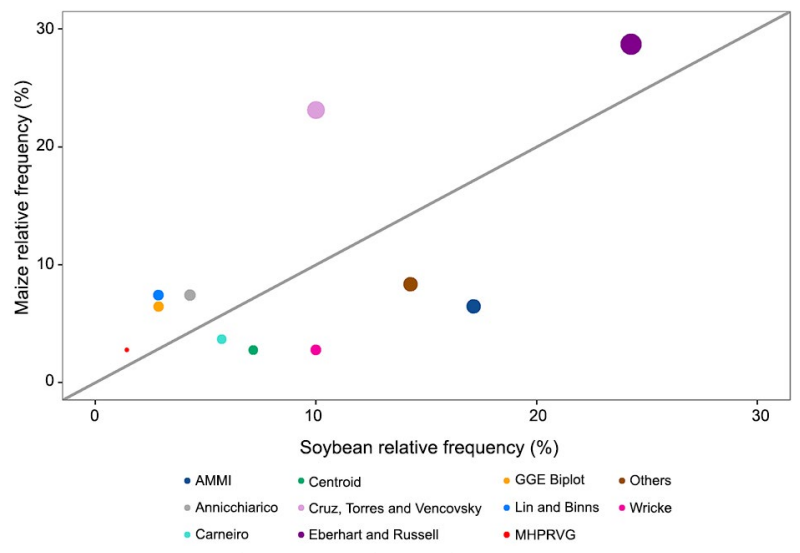

Figure 3 - Relative frequency of use of each method in relation to the number of articles on adaptability and stability in maize and soybean. The point size is directly proportional to the number of articles using each method. Methods below the diagonal line predominated in soybean and methods above predominated in maize.

to this method, genotypes with high predictability (stable) are those that have a variance in the regression deviation statistically equal to zero. Furthermore, the genotypes can be classified as well adapted to favorable environments $\left(\beta_{i}>1\right)$, well adapted to unfavorable environments $\left(\beta_{i}<1\right)$ or widely adapted $\left(\beta_{i}=1\right.$; Cruz et al., 2012). The Eberhart and Russell method has been widely used in the last decades in many crops, such as bean, maize and wheat (Alawa et al., 2010; Bornhofen et al., 2017; Carneiro et al., 2018).

The Cruz, Torres, and Vencovsky (CTV) method, proposed in 1989 (Cruz et al., 1989) was the second most used (32 articles). Its adoption was found mainly in articles related to maize. Similar to the Eberhart and Russell method, CTV is based on linear regression, but is a bi-segmented regression. For this reason, this method has a specific parameter for adaptability to unfavorable environments $\left(\beta_{1}\right)$ and a second parameter for adaptability to favorable environments $\left(\beta_{1}+\beta_{2}\right)$, besides the variance of the regression deviation $\left(\sigma_{d i}^{2}\right.$; Cruz et al., 1989). Thus, this method offers a more detailed understanding of genotype adaptability and, consequently, allows for identification of genotypes simultaneously adapted to favorable $\left(\beta_{1}+\beta_{2}>1\right)$ and unfavorable environments $\left(\beta_{1}\right.$ $<1$ ). This additional information can be considered as an advantage in relation to Eberhart and Russell, which is a possible reason for this method being widely used.

Although CTV is more informative than Eberhart and Russell, as previously mentioned, the number of articles that used CTV was lower. CTV is more recent and less widespread than Eberhart and Russell, which may justify its lower adoption rate. In addition, CTV has one more parameter than Eberhart and Russell, which can represent greater difficulty in the interpretation of results and recommendation of cultivars by plant breeders.

The Additive Main Effects and Multiplicative Interaction (AMMI) method, proposed in 1988 (Zobel et al., 1988), was the third most used (19 articles). Its adoption was found mainly in articles on soybean. The AMMI method combines analysis of variance for the main effects (genotype and environment) and principal component analysis for the GE interaction effect (Gauch and Zobel, 1996). This method combines both additive (main effects) and multiplicative components (GE interaction effect). Due to this approach, AMMI allows for a more detailed and accurate analysis of the GE interaction because it partitions the original sum of squares $\left(\mathrm{SS}_{\mathrm{GE}}\right)$ in two parts, called pattern and noise (Elias et al., 2016; Gauch and Zobel, 1996).

Another advantage of the AMMI method is the easy interpretation of the results, due to its simultaneous graphical representation of the genotypes and environments in the biplots. Therefore, this method is able to both identify widely-adapted genotypes and subdivide the growing region into relatively homogeneous mega-environments (Gauch and Zobel, 1996).

The nonparametric methods listed, especially Lin and Binns, Annicchiarico, Carneiro and Centroid methods, were also used extensively (39 articles). These methods do not require assumptions relating 
to phenotypic values distribution, such as normality of residuals and homogeneity of variances, that are required by the parametric methods, such as Eberhart and Russell (Yue et al., 1997). In addition, nonparametric methods generally do not have many parameters to express genotype performance, which facilitates their interpretation (Elias et al., 2016; Nascimento et al., 2009). However, in methods with many parameters, such as Eberhart and Russell and CTV, this difficulty can be solved by using computational intelligence. For example, Carneiro et al. (2018) used fuzzy logic, a computational intelligence technique, to classify the genotypes into easy to interpret classes using the parameters from the Eberhart and Russell method $\left(\beta_{0}, \beta_{1}\right.$ and $\left.\mathrm{R}^{2}\right)$.

In both maize and soybean crops, no article was found from the 1970s (Figure 4). Note that the dashed line in the same figure showed that in the 1980s, two articles on maize and two articles on soybean were found. The number of articles published per decade increased until the 2000s (2000-2009). In this decade, the average annual rate of publications on soybean and maize was 2.1 and 4.1 , respectively. In the 2010s (2010-2017), the number of publications addressing adaptability and stability in maize or soybean had decreased considerably. In this decade, the average annual rate of publications on soybean and maize was 1.1 and 2.4 , respectively.

Scientific output and the number of scientific articles published, including in Agricultural Sciences, have increased sharply in the last decades in both Brazil and the world (Sidone et al., 2016). Certainly, this increase contributed to a greater number of published articles on GE interaction. Whatsmore, the relevance given by researchers to the GE interaction has probably increased over the last few decades. Of the 21 listed methods in this work, 16 were proposed between 1985 and 2005, a period that belonged to the decades in which there was an increase in the number of articles published on adaptability and stability (1980-1989 to 2000-2009). The decrease in the number of publications on adaptability and stability in the

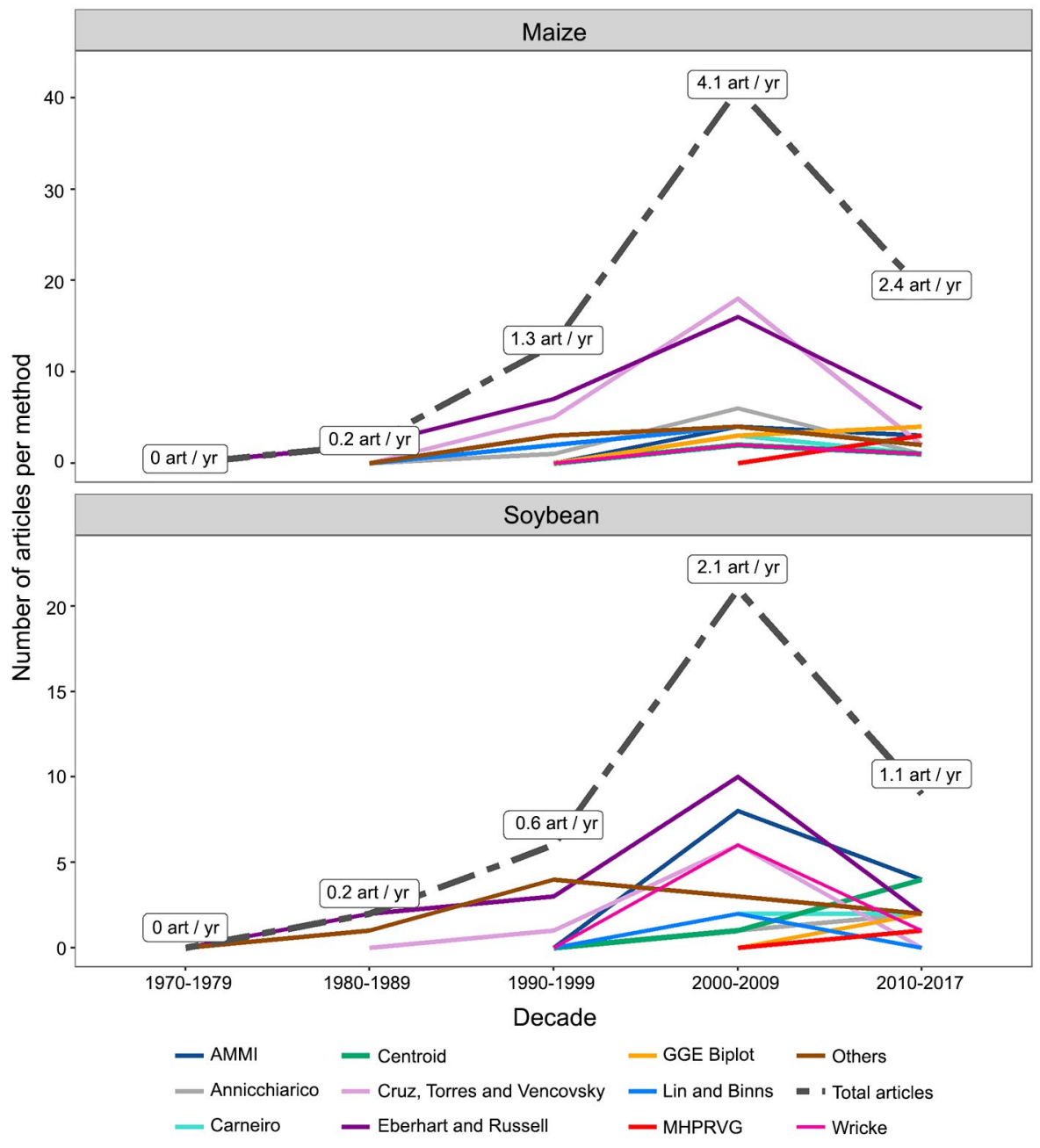

Figure 4 - Number of articles published on adaptability and stability, average annual rate of publications and the number of publications using each method, considering maize and soybean crops and different decades. 
current decade (2010-2017) probably indicates less interest on the part of the Brazilian scientific journals or Brazilian researchers on this subject. Although studies on adaptability and stability continue to be extremely important for plant breeding, there are more recent subjects that attract more attention in the scientific community. On the other hand, the international scientific community has realized the need to continue publishing articles on this subject. For example, Crop Science published in 2016 an issue exclusively dedicated to this topic (https:// dl.sciencesocieties.org/publications/cs/tocs/56/5).

In both crops, the Eberhart and Russell method has been widely used since its first publication in the 1980s. In maize, the CTV method has also been widely used since the 1990s. In soybean, the AMMI method has also been widely used since the 2000s. The number of publications on adaptability and stability has been decreasing in the current decade and, as with Eberhart and Russell, the number of publications using CTV, AMMI and most other methods also decreased. Although the scientific literature discusses a number of advantages using the more recent methods its adoption has not proven more popular than the most wellestablished method (Eberhart and Russell).

However, even with the decrease in the number of publications, the number of articles using certain methods increased in the current decade - GGE biplot and MHPRVG (harmonic mean) in maize and GGE biplot, Centroid, and MHPRVG in soybean. Eeuwijk et al. (2016) reported research from numerous citations of several methods between 2013 and 2015 in the Web of Science database. The researchers found that the most used methods were those based on multivariate analysis, such as AMMI and GGE biplot, as well as those based on mixed models, which is the statistical approach to which the MHPRVG belongs.

The GGE biplot method, which is considered a modification of the AMMI method, interprets the genotype effect $(\mathrm{G})$ and the GE interaction effect (GE) using principal component analysis (PCA) while the AMMI uses PCA to interpret only the GE interaction effect (Balestre et al., 2009; Yan et al., 2000). There are several studies comparing AMMI and GGE biplot, but researchers do not agree on which method is most optimal (Balestre et al., 2009; Gauch et al., 2008; Yan et al., 2007). According to Eeuwijk et al. (2016), both methods are very useful in the study of GE interaction and the reasons for preferring one or the other are of minor importance. These authors state that GGE biplot has the advantage of exploiting all the variation related to the genotype (G and GE). On the other hand, AMMI has the advantage of showing in more detail part of the GE interaction of the phenotypic variation; that is, only the GE. Although both methods are similar and efficient, only the GGE biplot showed an increase in the number of articles in the current decade. Possibly, this result is because GGE biplot requires more research and information, since it is a newer and less commonly utilized method in Brazil.

The methods based on mixed method, such as MHPRVG, are focused on modeling the GE interaction for heterogeneity of variance and covariance (Malosetti et al., 2013). Thus, one of their advantages is the ability to analyze unbalanced trials (Mendes et al., 2012). The mixed models also allow for the inclusion of pedigree or marker information in the variance-covariance matrix, as well as correlation across environments (Crossa et al., 2006; Eeuwijk et al., 2016). The increase in the number of articles using MHPRVG can be explained by the advantages of the mixed models and by the recent adoption of this method in studies on adaptability and stability in Brazil. Among the articles considered in this study, the first article to use this method was published in 2012.

The Centroid method is a nonparametric method that compares the cartesian distance between genotypes and four ideotypes created based on experimental data (Rocha et al., 2005). The ideotypes represent the hypothetical genotypes of maximum general adaptability, minimal adaptability and specific adaptability to favorable or unfavorable environments. Nascimento et al. (2009) proposed the inclusion of three additional ideotypes with a greater biological sense - average wide adaptability and average adaptability to favorable or unfavorable environments. The Centroid method facilitates cultivar recommendations, as it allows for directing genotypes (identification of the best genotypes) according to environmental variations. It uses only a few parameters in contrast with the Eberhart and Russell method, and does not induce duplicity (uncertainty) in the interpretation of the results, as in the case of Lin and Binns (Nascimento et al., 2009). These advantages combined with the fact that the centroid method was only recently proposed may be the reason for its growth in the present decade.

There are other statistical approaches experiencing increasing adoption rates to study adaptability and stability, such as Bayesian models (Barroso et al., 2016) and artificial neural networks (Corrêa et al., 2016). However, there were no articles found in maize or soybean that used these approaches.

The average number of methods used in the articles with maize was 1.4 , and $66.7 \%$ of these articles used only one method. In soybean, the average number of methods was 1.8 , and $50 \%$ of these articles used only one method.

Adaptability and stability methods are considered as alternatives and others as complementary. These complementary methods can be used together. For example, a number of studies have shown that the Wricke method and the Plaisted and Peterson method are redundant, with suggestions that they are considered as alternatives (Cruz et al., 2012; Silva and Duarte, 2006). On the other hand, certain researchers consider the Eberhart and Russell method and the 
AMMI method as complementary, since the Eberhart and Russell method assesses the responsiveness of each genotype to the improvements in the environment and the AMMI estimates of the genotype contribution to the GE interaction without noise (Silva and Duarte, 2006). Thus, the joint use of Eberhart and Russell and AMMI may be a good strategy for a more comprehensive understanding of the GE interaction.

According to the equivalence coefficient $\left(\mathrm{E}_{\mathrm{ij}}\right)$, certain methods showed strong association, which demonstrate a high probability of being used together in studies of more than one method (Figure 5). A strong association was observed between nonparametric methods (Lin and Binns, Annicchiarico, Centroid and Carneiro), between multivariate methods (AMMI and GGE Biplot) and between methods based on regression (Eberhart and Russell and CTV). Therefore, the associations found were mainly between methods with the same statistical approach.

However, methods with the same statistical approach usually tend to show strong agreement with each other (Cargnelutti Filho et al., 2009; Silva and Duarte, 2006). In general, these methods do not provide additional information because they are similar. Thus, the joint use of methods with the same statistical approach usually does not contribute to an appropriate cultivar recommendation. Moreover, Silva and Duarte (2006) reported a strong association between the nonparametric methods of Annicchiarico and Lin and Binns. The researchers did not recommend the simultaneous use of these methods. Moreover, Cargnelutti et al. (2009) found strong agreement between the estimates of adaptability and stability parameters of several methods based on regression (Eberhart and Russell, Silva and Barreto, CTV, etc.).
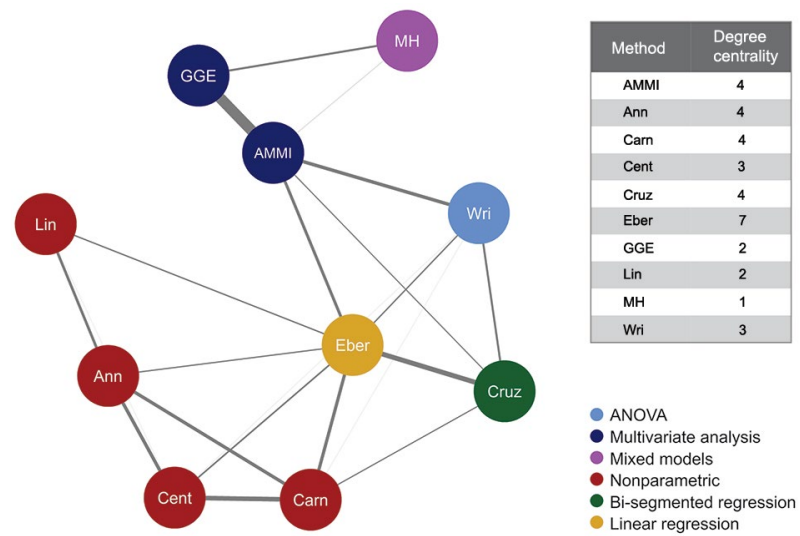

Figure $\mathbf{5}$ - Association network between methods, according to the statistical approach, based on the equivalence coefficient (Eij), and the degree centrality of each method (number of connections with $\mathrm{Eij} \geq 0.015) . \mathrm{AMMl}=\mathrm{AMMl} ; \mathrm{Ann}=$ Annicchiarico; Carn = Carneiro; Cent = Centroid; Cruz = Cruz, Torres, and Vencovsky; Eber = Eberhart and Russell; GGE = GGE Biplot; Lin = Lin and Binns; MH $=$ MHPRVG; Wri $=$ Wricke.
In several articles in which more than one method was used, the choice of methods was not based on the complementarity of the information. Instead, the choice may have been based on a comparison of similar methods, or a ratification of the results found by one method when using another method. For example, Oliveira et al. (2010) aimed to study the adaptability and stability of maize hybrids and also aimed to compare the AMMI and GGE Biplot multivariate methods.

The Eberhart and Russell method showed the greatest degree of centrality for the association network. The vertices in the graph - in this case, the methods - that show a higher degree of agreement or more connections are more central in the structure and tend to have more ability to influence the others (Yan and Ding, 2009). As Eberhart and Russell is the most widespread method, it has usually been a reference in studies that compares cultivar recommendations using more than one method. In addition, there are reports of complementarity of Eberhart and Russell with several other methods, such as AMMI, Lin and Binns, Annicchiarico and MHPRVG (Paula et al., 2014; Silva and Duarte, 2006).

\section{Conclusions}

The predominant method in the study of adaptability and stability was the Eberhart and Russell. The CTV and AMMI methods were also widely used. In addition, the adoption of GGE Biplot, MHPRVG and Centroid methods has increased in the current decade.

The adaptability and stability of maize and soybean has been widely studied within the last few decades in Brazil. However, in the current decade there has been a decrease in the number of publications on this subject.

\section{Acknowledgments}

This research was supported by the Brazilian National Council for Scientific and Technological Development (CNPq), the Coordination for the Improvement of Higher Level Personnel (CAPES) and the Federal University of Viçosa (UFV).

\section{Authors' Contributions}

Conceptualization: Cruz, C.D.; Rezende, W.S. Data acquisition: Rezende, W.S. Data analysis: Rezende, W.S.; Cruz, C.D. Design of methodology: Rezende, W.S.; Cruz, C.D.; Borém, A.; Rosado, R.D.S. Writing and editing: Rezende, W.S.; Cruz, C.D.; Borém, A.; Rosado, R.D.S.

\section{References}

Alawa, S.; Kwolek, T.; McPherson, M.; Pellow, J.; Meyer, D. 2010. A comprehensive comparison between Eberhart and Russell joint regression and GGE biplot analyses to identify stable and high yielding maize hybrids. Fields Crop Research 119: 225-230. 
Alliprandini, L.F.; Abatti, C.; Bertagnolli, P.F.; Cavassim, J.E.; Gabe, H.L.; Kurek, A.; Matsumoto, M.N.; Oliveira, M.A.R.; Pitol, C.; Prado, L.C.; Steckling, C. 2009. Understanding soybean maturity groups in Brazil: environment, cultivar classification and stability. Crop Science 49: 801-808.

Balestre, M.; Von Pinho, R.G.; Souza, J.C.; Oliveira, R.L. 2009. Genotypic stability and adaptability in tropical maize based on AMMI and GGE biplot analysis. Genetics and Molecular Research 8: 1311-1322.

Barroso, L.M.A.; Teodoro, P.E.; Nascimento, M.; Torres, F.E.; Santos, A.; Corrêa, A.M.; Sagrilo, E.; Corrêa, C.C.G.; Silva, F.A.; Ceccon, G. 2016. Bayesian approach increases accuracy when selecting cowpea genotypes with high adaptability and phenotypic stability. Genetics and Molecular Research 15: 1-11.

Bornhofen, E.; Benin, G.; Storck, L.; Woyann, L.G.; Duarte, T.; Stoco, M.G.; Marchioro, S.V. 2017. Statistical methods to study adaptability and stability of wheat genotypes. Bragantia 76: 1-10.

Cargnelutti Filho, A.; Storck, L.; Riboldi, J.; Guadagnin, J.P. 2009. Association between adaptability and stability methods in corn. Ciência Rural 39: 340-347 (in Portuguese, with abstract in English).

Carneiro, V.Q.; Prado, A.L.; Cruz, C.D.; Carneiro, P.C.S.; Nascimento, M.; Carneiro, J.Q.S. 2018. Fuzzy control systems for decision-making in cultivars recommendation. Acta Scientiarum. Agronomy 40: 1-8.

Corrêa, A.M.; Teodoro, P.E.; Gonçalves, M.C.; Barroso, L.M.A.; Nascimento, M.; Santos, A.; Torres, F.E. 2016. Artificial intelligence in the selection of common bean genotypes with high phenotypic stability. Genetics and Molecular Research 15: 1-7.

Crossa, J.; Burgueño, J.; Cornelius, P.L.; Mclaren, G.; Trethowan, R.; Krishnamachari, A. 2006. Modeling genotype $x$ environment interaction using additive genetic covariances of relatives for predicting breeding values of wheat. Crop Science 46: 1722-1733.

Cruz, C.D.; Torres, R.A.; Vencovsky, R. 1989. An alternative approach to the stability analysis proposed by Silva and Barreto. Revista Brasileira de Genética 12: 567-580.

Cruz, C.D.; Regazzi, A.J.; Carneiro, P.C.S. 2012. Biometric models applied to genetic improvement $=$ Modelos biométricos aplicados ao melhoramento genético. 4ed. vol. 1. Editora UFV, Viçosa, MG, Brazil (in Portuguese).

Cruz, C.D.; Carneiro, P.C.S.; Regazzi, A.J. 2014. Biometric models applied to genetic improvement $=$ Modelos biométricos aplicados ao melhoramento genético. 3ed. vol. 2. Editora UFV, Viçosa, MG, Brazil (in Portuguese).

Eberhart, S.A.; Russell, W.A. 1966. Stability parameters for comparing varieties. Crop Science 6: 36-40.

Eeuwijk, F.A.; Bustos-Korts, D.V.; Malosetti, M. 2016. What should students in plant breeding know about the statistical aspects of genotype $\times$ environment interactions? Crop Science 56: 2119-2140.

Elias, A.A.; Robbins, K.R.; Doerge, R.W.; Tuinstra, M.R. 2016. Half a century of studying genotype $\times$ environment interactions in plant breeding experiments. Crop Science 56: 2090-2105.
Epskamp, S.; Cramer, A.O.J.; Waldorp, L.J.; Schmittmann, V.D.; Borsboom, D. 2012. qgraph: network visualizations of relationships in psychometric data. Journal of Statistical Software 48: 1-18.

Fruchterman, T.M.J.; Reingold, E.M. 1991. Graph drawing by force-directed placement. Software: Practice and Experience 21: 1129-1164.

Gauch, H.G.; Zobel, W. 1996. AMMI analysis of yield trials. p. 85-122. In: Kang, M.S.; Gauch, H.G., eds. Genotype by environment interaction. CRC Press, Boca Raton, FL, USA.

Gauch, H.G.; Piepho, H.P.; Annicchiarico, P. 2008. Statistical analysis of yield trials by AMMI and GGE: further considerations. Crop Science 48: 866-889.

Kang, M.J. 1988. A rank-sum method for selecting high-yielding, stable corn genotypes. Cereal Research Communications 16: 113-115.

Malosetti, M.; Ribaut, J.M.; Eeuwijk, F.A.V. 2013. The statistic analysis of multienvironment data: modeling genotype-byenvironment interaction and its genetic basis. Frontiers in Physiology 4: 1-17.

Medina, E.U.; Pailaquilén, R.M.B. 2010. Systematic review and its relationship with evidence-based practice in health. Revista Latino-Americana de Enfermagem 18: 824-831.

Mendes, F.F.; Guimarães, L.J.M.; Souza, J.C.; Guimarães, P.E.O.; Pacheco, C.A.P.; Machado, J.R.A.; Meirelles, W.F.; Silva, A.R.; Parentoni, S.N. 2012. Adaptability and stability of maize varieties using mixed methodology. Crop Breeding and Applied Biotechnology 12: 111-117.

Nascimento, M.; Cruz, C.D.; Campana, A.C.M.; Tomaz, R.S.; Salgado, C.C.; Ferreira, R.P. 2009. Alteration of the centroid method to evaluate genotypic adaptability. Pesquisa Agropecuária Brasileira 44: 263-269 (in Portuguese, with abstract in English).

Oliveira, R.L.; Von Pinho, R.G.; Balestre, M.; Ferreira, D.V. 2010. Evaluation of maize hybrids and environmental stratification by the methods AMMI and GGE biplot. Crop Breeding and Applied Biotechnology 10: 247-253.

Paula, T.O.M.; Marinho, C.D.; Souza, V.; Barbosa, M.H.P.; Peternelli, L.A.; Kimbeng, C.A.; Zhou, M.M. 2014. Relationships between methods of variety adaptability and stability in sugarcane. Genetics and Molecular Research 13: 4216-4225.

R Core Team. 2017. R: a language and environment for statistical computing. R Foundation for Statistical Computing, Vienna, Austria.

Resende, M.D.V. 2002. Biometric genetics and statistics in the breeding of perennial plants = Genética biométrica e estatística no melhoramento de plantas perenes. Embrapa Informação Tecnológica, Brasília, DF, Brazil (in Portuguese).

Rocha, R.B.; Muro-Abad, J.I.; Araújo, E.F.; Cruz, C.D. 2005. Evaluation of the Centroid method for study of environment adaptability of clones of Eucalyptus grandis. Ciência Florestal 15: 255-266 (in Portuguese, with abstract in English).

Schmildt, E.R.; Cruz, C.D. 2005. Adaptability and stability of maize using Eberhart and Russell and Annicchiarico methods. Revista Ceres 52: 45-58 (in Portuguese, with abstract in English). 
Sidone, O.J.G.; Haddad, E.A.; Mena-Chalco, J.P. 2016. Science in Brazilian regions: development of scholarly production and research collaboration networks. TransInformação 28: 15-31 (in Portuguese, with abstract in English).

Silva, W.C.J.; Duarte, J.B. 2006. Statistical methods to study phenotypic adaptability and stability in soybean. Pesquisa Agropecuária Brasileira 41: 23-30 (in Portuguese, with abstract in English).

Storck, L.; Vencovsky, R. 1994. Stability analysis on a bisegmented discontinuous model with measurement errors in the variables. Revista Brasileira de Genética 17: 75-81.

Tranfield, D.; Denyer, D.; Smart, P. 2003. Towards a methodology for developing evidence-informed management knowledge by means of systematic review. British Journal of Management 14: 207-222.

Wickham, H. 2009. ggplot2: Elegant Graphics for Data Analysis. Springer, New York, NY, USA.
Yan, W.; Hunt, L.A.; Sheng, Q.; Szlavnics, Z. 2000. Cultivar evaluation and mega-environment investigation based on the GGE Biplot. Crop Science 40: 597-605.

Yan, W.; Kang, M.S.; Ma, B.; Woods, S.; Cornelius, P.L. 2007. GGE biplot vs. AMMI analysis of genotype-by-environment data. Crop Science 47: 643-655.

Yan, E.; Ding, Y. 2009. Applying centrality measures to impact analysis: a co-authorship network analysis. Journal of the American Society for Information Science and Technology 60: 2107-2118.

Yue, G.L.; Roozeboom, K.L.; Schapaugh Jr., W.T.; Liang, G.H. 1997. Evaluation of soybean cultivars using parametric and nonparametric estimates. Plant Breeding 116: 271-275.

Zobel, R.W.; Wright, M.J.; Gauch, H.G. 1988. Statistical analysis of a yield trial. Agronomy Journal 80: 388-393. 